\title{
非定常強制熱対流場の形状設計問題の解法
}

片峯 英次 ${ }^{* 1}$ ，岡田 直也 ${ }^{* 2}$

\section{Solution to shape design problems of unsteady forced heat-convection fields}

\author{
Eiji KATAMINE*1 and Naoya OKADA ${ }^{* 2}$ \\ ${ }^{* 1}$ Department of Mechanical Engineering, National Institute of Technology, Gifu College \\ 2236-2 Kamimakuwa, Motosu-shi, Gifu 501-0495, Japan \\ ${ }^{* 2}$ Isuzu Engineering Co., Ltd. \\ 8 Tsuchidana, Fujisawa-shi, Kanagawa 252-0806, Japan
}

Received: 11 September 2017; Revised: 10 October 2017; Accepted: 25 October 2017

\begin{abstract}
This paper presents numerical solution to two shape design problems of unsteady forced heat-convection fields to control temperature to a prescribed distribution. In the first problem, the square error integral between the actual temperature distributions and the prescribed temperature distributions on the prescribed sub-domains during the specified period of time is used as the objective functional. In the second problem, a multi-objective shape optimization problem using normalized objective functional is formulated for the temperature distribution prescribed problem and the total dissipated energy minimization problem in the unsteady forced heat-convection fields. Shape gradient of these shape design problems is derived theoretically using the Lagrange multiplier method, adjoint variable method, and the formulae of the material derivative. Reshaping is carried out by the traction method proposed as an approach to solving shape optimization problems. Numerical analyses program for the shape design is developed based on FreeFem++, and the validity of proposed method is confirmed by results of 2D numerical analyses.
\end{abstract}

Keywords : Optimum design, Inverse problem, Computer aided design, Computational mechanics, Finite element method, Forced heat-convection field, Adjoint method, Traction method

\section{1. は じめ に}

機械構造物の設計において，伝熱特性の改善を目的とした熱対流場の形状最適化問題は，工学分野における重 要課題の一つである. 例えば, 電子機器においては, 部品の高密度化や機器の小型化による発熱密度増大に伴い, 冷却を目的した放熱量最大化の形状最適化問題はその代表例である。一方，熱対流場領域の指定した部分境界あ るいは部分領域において, 温度あるいは流速などの状態関数分布が目標の分布になるように境界形状を決定する 問題は，逆問題と呼ばれている。この逆問題は，実際の温度分布などの状態関数分布と目標関数分布の二乗誤差 積分を最小化させる形状設計問題として捉えれば，上記の形状最適化問題の範疇に属すると考えることができる.

著者らはこのような問題を数理モデルとして捉え，これまでに，熱対流場の部分領域における温度分布を目標 の温度分布にコントロールするように領域形状を決定する問題，あるいは部分境界において放熱量を最大化させ る形状決定問題 (片峯他, 2007), さらには, 温度分布コントロールと領域全体での散逸エネルギー最小化を目的と した多目的形状決定問題 (片峯他, 2013) の解法を提案し, その妥当性を確認してきた。これらの解析では, 感度解

No.17-00407 [DOI: 10.1299/transjsme.17-00407], J-STAGE Advance Publication date : 8 November, 2017

${ }^{*}$ 正員, 岐阜工業高等専門学校機械工学科（广501-0495 岐阜県本巣市上真桑 2236-2)

*2 岐阜工業高等専門学校（現 い寸 ゙ェエンジニアリング（株）（テ252-0806 神奈川県藤沢市土棚 8)）

E-mail of corresponding author: katamine@gifu-nct.ac.jp 
析が効率的な随伴変数法を利用し，また実際の形状最適化手法には，力法 (畔上, 1994)(あるいは $H^{1}$ 勾配法 (畔上, 2014))を用いた。 しかしながら，これまでに取り扱った問題は定常問題に限られていた。そこで本研究では，非 定常の熱対流場における形状設計問題の解法を試みる.

随伴変数法を利用した熱対流場における形状設計に関する研究は, 桃瀬ら (桃瀬他, 2009), Park ら (Park and Ku, 2001), (Park and Shin, 2003) によって行われている。桃瀬ら (桃瀬他, 2009) は，自然対流場の部分領域における速 度の最大化を設計目標としたときの形状感度解析法を提案しているが，定常問題の解法に限られている．Park ら (Park and Ku, 2001), (Park and Shin, 2003) は, 非定常自然対流場の形状同定問題の解析法を提案し, 数值解析では, 定常問題に対して，境界形状を表現する設計変数を極力少なく制限して解析する方法を示している．Yan ら (Yan and Gao, 2013), (Yan et al., 2015) は，強制熱対流場の形状最適化を随伴変数法を利用して行っているが，解析は定 常問題に限られている.一方, 随伴変数法を利用した熱対流場のトポロジー形状最適化解析が, Yaji ら (Yaji et al., 2015), Alexandersen ら (Alexandersen et al., 2014) によって行われている. Yaji ら (Yaji et al., 2015) は強制対流場 に関するトポロジー最適化, Alexandersen ら (Alexandersen et al., 2014) は自然対流場に関するトポロジー最適化 を行っているが，いずれの解析も定常問題に限られている．また，Yan らは Gauss-Newton 法に基づく直接微分法 (Yan et al., 2014), あるいは随伴変数法 (Yan et al., 2017) を用いて, 非定常移流拡散場における形状同定問題の数 值解析法を提案しているが，対流場における移流の大きさは，支配方程式から評価される状態変数ではなく，場 所の関数として簡略化した問題としての数值解析結果が示されている. さらに, 最近になって, 久保田ら (久保田 他, 2017) は, 非定常熱対流場における伝熱性能改善のための形状感度解析法を提案し, 実機部品へ適用した数值 解析例を示している.

本研究では, 非定常の強制熱対流場に対して, 部分領域において温度分布履歴を規定する形状設計問題を取り上げ て，その解法を提案する。強制熱対流場の移流の大きさは簡略化せずに，支配方程式である連続の式， Navier-Stokes 方程式，エネルギー方程式から評価される状態変数として取り扱われる.

本論文では，二つの問題を取り上げる。最初の問題として，指定された部分領域において実際の温度分布履歴と 指定された温度分布履歴の 2 乗誤差積分を最小化する問題 (温度分布履歴規定問題) を定式化し, Lagrange 乗数法 あるいは随伴変数法および物質導関数を利用して形状修正の感度となる形状勾配密度関数を導出する。 二つ目の 問題として，部分領域における温度分布履歴規定と流れ場領域全体ので散逸エネルギー最小化 (片峯, 畔上, 1994), (Katamine et al., 2005) の多目的問題を取り上げて，同様な手順によって，この問題に対する形状勾配密度関数を 導出する. 最後に, 上記の二つの問題に対して導出された形状勾配密度関数に基づいて，力法 (畔上, 1994)（あ るいは $H^{1}$ 勾配法 (畔上, 2014)）を適用した解析例を紹介する。本研究における数值解析では, Freefem++(Hecht, 2012),(大塚, 高石, 2014) に基づいてプログラム開発を行い，本論文では 2 次元問題の簡単な解析結果を紹介する.

\section{2. 非定常強制熱対流場の支配方程式}

$\mathbb{R}^{d}(d=2,3)$ の領域 $\Omega$, 時間 $[0, T]$ における非定常強制熱対流場を考える. 空間 $\vec{x} \in \Omega$, 時間 $t \in[0, T]$ における 流速分布 $u_{i}(\vec{x}, t)$, 圧力分布 $p(\vec{x}, t)$, 温度分布 $\theta(\vec{x}, t)$ を解析することを考える. 非定常強制熱対流場の支配方程式 として, 無次元化された Navier-Stokes 方程式, 連続の式, およびエネルギー方程式を考え, それらの支配方程式 の弱形式は, 随伴流速 $w_{i}(\vec{x}, t)$, 随伴圧力 $q(\vec{x}, t)$, 随伴温度 $\xi(\vec{x}, t)$ を用いて, 次のように表すことができる.

$$
\begin{aligned}
& \int_{0}^{T}\left\{t^{V}\left(u_{,}, w\right)+a^{V}(u, w)+b^{V}(u, u, w)+c(w, p)-l(w)\right\} d t=0 \quad \forall w \in W \\
& \int_{0}^{T}\{c(u, q)\} d t=0 \quad \forall q \in Q \\
& \int_{0}^{T}\left\{t^{H}\left(\theta_{t,}, \xi\right)+a^{H}(\theta, \xi)+b^{H}(u, \theta, \xi)+f_{q}^{H}(\xi)+f_{h}^{H}(\theta, \xi)-f_{h f}^{H}(\xi)\right\} d t=0 \quad \forall \xi \in \Xi
\end{aligned}
$$

ただし, $t^{V}\left(u_{t, t}, w\right), a^{V}(u, w), b^{V}(v, u, w), c(w, p), l(w), t^{H}\left(\theta_{t}, \xi\right), a^{H}(\theta, \xi), b^{H}(u, \theta, \xi), f_{q}^{H}(\xi), f_{h}^{H}(\theta, \xi), f_{h f}^{H}(\xi)$ は 次のように定義されている. 


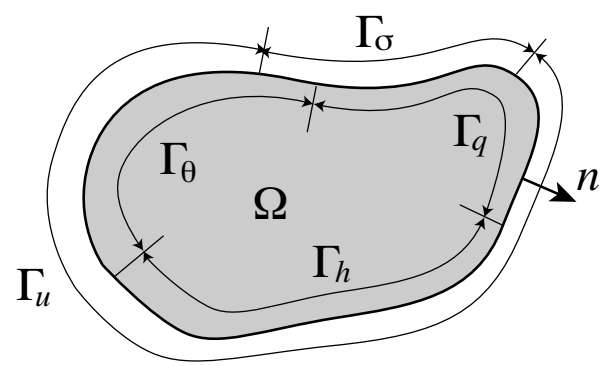

Fig. 1 Heat-convection field

$$
\begin{aligned}
& t^{V}\left(u_{,}, w\right)=\int_{\Omega} w_{i} \frac{\partial u_{i}}{\partial t} d x, \quad a^{V}(u, w)=\int_{\Omega} \frac{1}{R e} w_{i, j} u_{i, j} d x, \quad b^{V}(v, u, w)=\int_{\Omega} w_{i} v_{j} u_{i, j} d x, \\
& c(w, p)=-\int_{\Omega} w_{i, i} p d x, \quad l(w)=\int_{\Gamma_{\sigma}} w_{i} \hat{\sigma}_{i} d \Gamma, \\
& t^{H}\left(\theta_{, t}, \xi\right)=\int_{\Omega} \xi \frac{\partial \theta}{\partial t} d x, \quad a^{H}(\theta, \xi)=\int_{\Omega} \frac{1}{\operatorname{RePr}} \xi_{, i} \theta_{, i} d x, \quad b^{H}(u, \theta, \xi)=\int_{\Omega} \xi u_{j} \theta_{, j} d x, \\
& f_{q}^{H}(\xi)=\int_{\Gamma_{q}} \xi \hat{q} d \Gamma \quad f_{h}^{H}(\theta, \xi)=\int_{\Gamma_{h}} \hat{h} \xi \theta d \Gamma, \quad f_{h f}^{H}(\xi)=\int_{\Gamma_{h}} \hat{h} \xi \hat{\theta}_{f} d \Gamma
\end{aligned}
$$

ここで，本論文のテンソル表示では Einstein の総和規約と偏微分表示 $(\cdot)_{, i}=\partial(\cdot) / \partial x_{i}$ を使用し， $(\cdot)_{, t}$ は時間の導 関数を表わしている.

また，領域 $\Omega$ の境界 $\Gamma$ は，図 1 のように，流れ場の境界条件に関して基本境界 $\Gamma_{u}$ と自然境界 $\Gamma_{\sigma}$, 温度場に関 しては基本境界 $\Gamma_{\theta}$, 熱流束境界 $\Gamma_{q}$, 熱伝達境界 $\Gamma_{h}$ によって構成され，その境界条件，初期条件は，次のように定 義されている.

$$
\begin{aligned}
& u_{i}(\vec{x}, t)=\hat{u}_{i}(\vec{x}, t), \quad t \in[0, T], \vec{x} \in \Gamma_{u} \\
& \sigma_{i}(\vec{x}, t)=\hat{\sigma}_{i}(\vec{x}, t)=\left(-p \delta_{i j}+\frac{1}{R e} u_{i, j}\right) n_{j}=0, \quad t \in[0, T], \vec{x} \in \Gamma_{\sigma} \\
& \theta(\vec{x}, t)=\hat{\theta}(\vec{x}, t), \quad t \in[0, T], \vec{x} \in \Gamma_{\theta} \\
& -\frac{1}{\operatorname{RePr}} \theta(\vec{x}, t),{ }_{j} n_{j}=\hat{q}(\vec{x}, t), \quad t \in[0, T], \vec{x} \in \Gamma_{q} \\
& -\frac{1}{\operatorname{RePr}} \theta(\vec{x}, t),{ }_{j} n_{j}=\hat{h}\left(\theta(\vec{x}, t)-\hat{\theta_{f}}\right), \quad t \in[0, T], \vec{x} \in \Gamma_{h} \\
& u_{i}(\vec{x}, 0)=u_{i_{i n i}}(\vec{x}), \quad \vec{x} \in \Omega, \quad p(\vec{x}, 0)=p_{\text {ini }}(\vec{x}), \quad \vec{x} \in \Omega, \quad \theta(\vec{x}, 0)=\theta_{\text {ini }}(\vec{x}), \quad \vec{x} \in \Omega
\end{aligned}
$$

ただし， Re, Pr はそれぞれレイノルズ数，プラントル数を表す。 $\hat{q}$ は熱流束， $\hat{h}$ は熱伝達率， $\hat{\theta}_{f}$ は外気温度， $u_{i_{i n i}}$ は初期流速, $p_{i n i}$ は初期圧力, $\theta_{i n i}$ は初期温度を表している. また $n_{j}$ は境界における単位法線ベクトル, $(\hat{P})$ は境 界における既知関数を表している。

また，流速 $u_{i}$, 随伴流速 $w_{i}$ などは，次の関数空間の要素とする.

$$
\begin{aligned}
U & =\left\{u(\vec{x}, t) \in H^{1}(\Omega \times[0, T]) \mid \quad u_{i}(\vec{x}, t)=\hat{u}_{i}(\vec{x}, t), t \in[0, T], \vec{x} \in \Gamma_{u}, \quad u_{i}(\vec{x}, 0)=u_{i_{i n i}}(\vec{x}), \vec{x} \in \Omega\right\} \\
Q & =\left\{q(\vec{x}, t) \in L^{2}\left(\int_{\Omega} q d x=0 \text { (if } \Gamma_{\sigma}=\emptyset\right)\right\} \\
\Theta & =\left\{\theta(\vec{x}, t) \in H^{1}(\Omega \times[0, T]) \mid \quad \theta(\vec{x}, t)=\hat{\theta}(\vec{x}, t), t \in[0, T], \vec{x} \in \Gamma_{\theta},\right. \\
& -\frac{1}{\operatorname{RePr}} \theta(\vec{x}, t),{ }_{j} n_{j}=\hat{q}(\vec{x}, t), t \in[0, T], \vec{x} \in \Gamma_{q}, \quad-\frac{1}{\operatorname{RePr}} \theta(\vec{x}, t),{ }_{j} n_{j}=\hat{h}\left(\theta(\vec{x}, t)-\hat{\theta}_{f}\right), \quad t \in[0, T], \vec{x} \in \Gamma_{h}, \\
& \left.\theta(\vec{x}, 0)=\theta_{\text {ini }}(\vec{x}), \vec{x} \in \Omega\right\}
\end{aligned}
$$




$$
\begin{aligned}
& W=\left\{w_{i}(\vec{x}, t) \in H^{1}(\Omega \times[0, T]) \mid \quad w_{i}(\vec{x}, t)=0, t \in[0, T], \vec{x} \in \Gamma_{u}, \quad w_{i}(\vec{x}, T)=0, \vec{x} \in \Omega\right\} \\
& \Xi=\left\{\xi(\vec{x}, t) \in H^{1}(\Omega \times[0, T]) \mid \quad \xi(\vec{x}, t)=0, t \in[0, T], \vec{x} \in \Gamma_{\theta}, \quad \xi(\vec{x}, T)=0, \vec{x} \in \Omega\right\}
\end{aligned}
$$

ここで, $H^{m}(\Omega \times[0, T])$ は $m$ 階の導関数まで領域 $\Omega \times[0, T]$ で 2 乗可積分な関数空間を表す.

\section{3. 非定常強制熱対流場の部分領域における温度分布履歴規定問題}

\section{$3 \cdot 1$ 問題の定式化}

部分領域 $\Omega_{D} \subset \Omega$ において, 時間 $t=t_{1} \in[0, T]$ から $t=t_{2} \in[0, T]$ における実温度分布 $\theta\left(\Omega_{D},\left[t_{1}, t_{2}\right]\right)$ と規定され た温度分布 $\theta_{D}\left(\Omega_{D},\left[t_{1}, t_{2}\right]\right)$ との 2 乗誤差を最小化する問題を定式化する. この熱対流場領域 $\Omega$ の領域変動を $\vec{T}_{s}(s$ は領域変動の履歴) で定義し, 領域 $\Omega$ は変動して $\Omega_{s}=\vec{T}_{s}(\Omega)$ になると仮定する. $\vec{T}_{s}(\Omega)$ は, 領域変動の制約を満た す適当に導関数が連続な許容関数空間 $D$ の要素とする. 簡単のために, 領域変動の制約に $\Omega_{D}$ と $\Gamma_{\sigma}$ が含まれる と仮定する。このとき, 時間 $t=t_{1}$ から $t=t_{2}$ における温度分布 2 乗誤差最小化問題は次のように定式化される.

$$
\begin{aligned}
\text { Given } & \Omega \\
\text { find } & \Omega_{s} \in D \\
\text { that minimize } & \int_{t_{1}}^{t_{2}} E_{\Omega_{D}}(\theta) d t \\
\text { subject to } & \int_{0}^{T}\left\{t^{V}\left(u_{, t}, w\right)+a^{V}(u, w)+b^{V}(u, u, w)+c(w, p)-l(w)\right\} d t=0 \\
& \int_{0}^{T}\{c(u, q)\} d t=0 \\
& \int_{0}^{T}\left\{t^{H}\left(\theta_{, t}, \xi\right)+a^{H}(\theta, \xi)+b^{H}(u, \theta, \xi)+f_{q}^{H}(\xi)+f_{h}^{H}(\theta, \xi)-f_{h f}^{H}(\xi)\right\} d t=0 \\
& \int_{\Omega} d x \leq M
\end{aligned}
$$

ただし，M は領域の大きさの上限值を表し，また $E_{\Omega_{D}}$ は次のように定義されている.

$$
E_{\Omega_{D}}(\theta)=\int_{\Omega_{D}}\left(\theta-\theta_{D}\right)^{2} d x
$$

なお, 時間区間 $\left[t_{1}, t_{2}\right]$ については, 温度分布履歴規定を試みる区間に応じて, 全時間区間 $[0, T]$ の中で任意に選定 できると仮定している，熱対流現象に対して，初期の過渡的な温度分布履歴規定を試みるのであれば， $\left[t_{1}, t_{2}\right]$ を区 間 $[0, T]$ の前半に設定し, 定常状態近くにおいて温度分布履歴規定を試みるのであれば, $\left[t_{1}, t_{2}\right]$ を区間 $[0, T]$ の後 半に設定することが可能である。

\section{$3 \cdot 2$ 形状勾配関数}

この問題は Lagrange 乗数法によって制約のない停留化問題に書き換えることができる．この場合の Lagrange 関 数 $L\left(u_{i}, p, \theta, w_{i}, q, \xi, \Lambda\right)$ は次式で与えられる.

$$
\begin{aligned}
& L=\int_{t_{1}}^{t_{2}} E_{\Omega_{D}}(\theta) d t \\
& -\int_{0}^{T}\left\{t^{V}\left(u_{, t}, w\right)+a^{V}(u, w)+b^{V}(u, u, w)+c(w, p)-l(w)\right\} d t-\int_{0}^{T}\{c(u, q)\} d t \\
& -\int_{0}^{T}\left\{t^{H}\left(\theta_{, t}, \xi\right)+a^{H}(\theta, \xi)+b^{H}(u, \theta, \xi)+f_{q}^{H}(\xi)+f_{h}^{H}(\theta, \xi)-f_{h f}^{H}(\xi)\right\} d t \\
& +\Lambda\left(\int_{\Omega} d x-M\right)
\end{aligned}
$$


領域変動に対する $L$ の導関数 $\dot{L}$ は速度場 $\vec{V}\left(\Omega_{s}\right)=\partial \vec{T}_{s} / \partial s(\Omega)=\partial \vec{T}_{s} / \partial s\left(\vec{T}_{s}^{-1}\left(\Omega_{s}\right)\right)$ を用いて，次のように得られる (畔上, 1994).

$$
\begin{aligned}
& \dot{L}=-\int_{0}^{T}\left\{t^{V}\left(u_{, t}, w^{\prime}\right)+a^{V}\left(u, w^{\prime}\right)+b^{V}\left(u, u, w^{\prime}\right)+c\left(w^{\prime}, p\right)-l\left(w^{\prime}\right)+c\left(u, q^{\prime}\right)\right\} d t \\
& -\int_{0}^{T}\left\{t^{H}\left(\theta_{, t}, \xi^{\prime}\right)+a^{H}\left(\theta, \xi^{\prime}\right)+b^{H}\left(u, \theta, \xi^{\prime}\right)+f_{q}^{H}\left(\xi^{\prime}\right)+f_{h}^{H}\left(\theta, \xi^{\prime}\right)-f_{h f}^{H}\left(\xi^{\prime}\right)\right\} d t \\
& -\int_{0}^{T}\left\{t^{V}\left(u_{, t}^{\prime}, w\right)+a^{V}\left(u^{\prime}, w\right)+b^{V}\left(u^{\prime}, u, w\right)+b^{V}\left(u, u^{\prime}, w\right)+c\left(u^{\prime}, q\right)+b^{H}\left(u^{\prime}, \theta, \xi\right)+c\left(w, p^{\prime}\right)\right\} d t \\
& -\int_{0}^{T}\left\{t^{H}\left(\theta_{, t}^{\prime}, \xi\right)+a^{H}\left(\theta^{\prime}, \xi\right)+b^{H}\left(u, \theta^{\prime}, \xi\right)+f_{h}^{H}\left(\theta^{\prime}, \xi\right)\right\} d t+\int_{t_{1}}^{t_{2}} E_{\Omega_{D}}\left(\theta^{\prime}\right) d t \\
& +\dot{\Lambda}\left(\int_{\Omega} d x-M\right)+l_{G}(\vec{V}) .
\end{aligned}
$$

ただし，(·的は空間座標に固定した分布関数の領域変動に対する導関数を表す。また，

$$
\begin{aligned}
& l_{G}(\vec{V})=\int_{\Gamma} G \vec{n} \cdot \vec{V} d \Gamma \\
& \begin{array}{l}
G=\int_{0}^{T}\left\{-\frac{1}{\operatorname{Re}} w_{i, j} u_{i, j}+w_{i, i} p\right. \\
\left.\quad-\frac{\partial \theta}{\partial t} \xi-\xi u_{j} \theta_{, j}-\frac{1}{\operatorname{RePr}} \xi_{, i} \theta_{, i}-\nabla_{n}(\xi \hat{q})-(\xi \hat{q}) \kappa-\nabla_{n}(\hat{h} \xi \theta)-(\hat{h} \xi \theta) \kappa+\nabla_{n}\left(\hat{h} \xi \hat{\theta}_{f}\right)+\left(\hat{h} \xi \hat{\theta}_{f}\right) \kappa\right\} d t+\Lambda
\end{array}
\end{aligned}
$$

ただし， $\nabla_{n}(\cdot) \equiv \nabla(\cdot) \cdot \vec{n}, \kappa$ は境界における平均曲率の $d-1$ 倍である。ここで, $u_{i}, p, \theta, w_{i}, q, \xi, \Lambda$ は次の KuhnTucker 条件

$$
\begin{aligned}
& \int_{0}^{T}\left\{t^{V}\left(u_{, t}, w^{\prime}\right)+a^{V}\left(u, w^{\prime}\right)+b^{V}\left(u, u, w^{\prime}\right)+c\left(w^{\prime}, p\right)-l\left(w^{\prime}\right)+c\left(u, q^{\prime}\right)\right\} d t=0 \quad \forall w^{\prime} \in W, \forall q^{\prime} \in Q \\
& \int_{0}^{T}\left\{t^{H}\left(\theta_{, t}, \xi^{\prime}\right)+a^{H}\left(\theta, \xi^{\prime}\right)+b^{H}\left(u, \theta, \xi^{\prime}\right)+f_{q}^{H}\left(\xi^{\prime}\right)+f_{h}^{H}\left(\theta, \xi^{\prime}\right)-f_{h f}^{H}\left(\xi^{\prime}\right)\right\} d t=0 \quad \forall \xi^{\prime} \in \Xi \\
& \int_{0}^{T}\left\{t^{V}\left(u_{, t}^{\prime}, w\right)+a^{V}\left(u^{\prime}, w\right)+b^{V}\left(u^{\prime}, u, w\right)+b^{V}\left(u, u^{\prime}, w\right)+c\left(u^{\prime}, q\right)+b^{H}\left(u^{\prime}, \theta, \xi\right)+c\left(w, p^{\prime}\right)\right\} d t=0 \quad \forall u^{\prime} \in U, \forall p^{\prime} \in Q \\
& \int_{0}^{T}\left\{t^{H}\left(\theta_{, t}^{\prime}, \xi\right)+a^{H}\left(\theta^{\prime}, \xi\right)+b^{H}\left(u, \theta^{\prime}, \xi\right)+f_{h}^{H}\left(\theta^{\prime}, \xi\right)\right\} d t-\int_{t_{1}}^{t_{2}} E_{\Omega_{D}}\left(\theta^{\prime}\right) d t=0 \quad \forall \theta^{\prime} \in \Theta \\
& \Lambda \geq 0, \quad \int_{\Omega} d x \leq M, \quad \Lambda\left(\int_{\Omega} d x-M\right)=0
\end{aligned}
$$

によって決定されたとき, Lagrange 汎関数の導関数は評価関数の導関数と一致して, 次の関係が成立する.

$$
\left.\dot{L}\right|_{u_{i}, p, \theta, w_{i}, q, \xi, \Lambda}=\left.\dot{E}_{\Omega_{D}}\right|_{u_{i}, p, \theta, w_{i}, q, \xi, \Lambda}=l_{G}(\vec{V})
$$

式 (25) で与えられる $G \vec{n}$ は, 評価関数の導関数において, 領域の微小変動を与える速度場 $\vec{V}$ の係数関数になって いることから，この問題における感度関数あるいは形状勾配関数と呼ばれる. また， スカラー関数 $G$ を形状勾配 密度関数と呼ぶ.

式(27) は状態方程式における Navier-Stokes 方程式と連続の式の弱形式, 式 (28) は状態方程式におけるエネルギー 方程式の弱形式, 式 (29) は随伴方程式における Navier-Stokes 方程式と連続の式の弱形式, 式 (30) は随伴方程式に おけるエネルギー方程式の弱形式を表わしている.これらの方程式から $u_{i}, p, \theta, w_{i}, q, \xi, \Lambda$ を解析して, 形状勾配関 数が評価できれば，力法を適用することが可能となる.

また，随伴方程式における連続の式を考慮し，設計境界では流速 $u_{i}=0$ と仮定すると，形状勾配密度関数 $G$ は 
次のように表すことができる.

$$
G=\int_{0}^{T}\left\{-\frac{1}{R e} w_{i, j} u_{i, j}-\frac{\partial \theta}{\partial t} \xi-\frac{1}{R e P r} \xi_{, i} \theta_{, i}-\nabla_{n}(\xi \hat{q})-(\xi \hat{q}) \kappa-\nabla_{n}(\hat{h} \xi \theta)-(\hat{h} \xi \theta) \kappa+\nabla_{n}\left(\hat{h} \xi \hat{\theta}_{f}\right)+\left(\hat{h} \xi \hat{\theta}_{f}\right) \kappa\right\} d t+\Lambda
$$

\section{4. 部分領域における温度分布履歴規定と散逸エネルギー最小化の多目的問題}

\section{$4 \cdot 1$ 問題の定式化}

部分領域 $\Omega_{D} \subset \Omega$ において, 時間 $t=t_{1}$ から $t=t_{2}$ における実温度分布 $\theta\left(\Omega_{D \theta},\left[t_{1}, t_{2}\right]\right)$ と規定された温度分布 $\theta_{D}\left(\Omega_{D \theta},\left[t_{1}, t_{2}\right]\right)$ との 2 乗誤差, および全領域 $\Omega$ において, 時間 $t=t_{1}$ から $t=t_{2}$ における散逸エネルギーを最小 化 (片峯, 畔上, 1994), (Katamine et al., 2005) する多目的形状最適化問題を定式化する.

簡単のために, 重み係数法に基づく手法に従って, 領域変動の制約に $\Omega_{D}$ が含まれると仮定する.

このとき, 時間 $t=t_{1}$ から $t=t_{2}$ における温度分布 2 乗誤差と散逸エネルギーを最小化する多目的問題は次のよ うに定式化される。

$$
\begin{aligned}
\text { Given } & \Omega \\
\text { find } \quad & \Omega_{s} \in D \\
\text { that minimize } & w \theta \cdot \frac{\int_{t_{1}}^{t_{2}} E_{\Omega_{D}}(\theta) d t}{\left[\int_{t_{1}}^{t_{2}} E_{\Omega_{D}}(\theta) d t\right]_{i n i}}+w_{u} \cdot \frac{\int_{t_{1}}^{t_{2}} E_{\Omega}(u) d t}{\left[\int_{t_{1}}^{t_{2}} E_{\Omega}(u) d t\right]_{i n i}} \\
\text { subject to } & \int_{0}^{T}\left\{t^{V}\left(u_{, t}, w\right)+a^{V}(u, w)+b^{V}(u, u, w)+c(w, p)-l(w)\right\} d t=0 \\
& \int_{0}^{T}\{c(u, q)\} d t=0 \\
& \int_{0}^{T}\left\{t^{H}\left(\theta_{,}, \xi\right)+a^{H}(\theta, \xi)+b^{H}(u, \theta, \xi)+f_{q}^{H}(\xi)+f_{h}^{H}(\theta, \xi)-f_{h f}^{H}(\xi)\right\} d t=0 \\
& \int_{\Omega} d x \leq M
\end{aligned}
$$

ただし， $E_{\Omega}(u), \varepsilon(u)$ は次のように定義されている.

$$
\begin{array}{r}
E_{\Omega}(u)=\int_{\Omega} 2 \frac{1}{R e} \varepsilon(u) \varepsilon(u) d x \\
\varepsilon(u)=\frac{1}{2}\left(u_{i, j}+u_{j, i}\right)
\end{array}
$$

また， $w_{\theta}, w_{u}$ はそれぞれ温度規定，散逸エネルギー最小化のための重み係数， $\left[\int_{t_{1}}^{t_{2}} E_{\Omega_{D}}(\theta) d t\right]_{i n i}, \quad\left[\int_{t_{1}}^{t_{2}} E_{\Omega}(u) d t\right]_{i n i}$ はそれぞれ温度分布 2 乗誤差の初期値, 散逸エネルギーの初期值であり, 式 (35) は正規化された目的汎関数になっ ている。

\section{2 形状勾配関数と随伴方程式}

前述と同様な手順によって, この問題の Lagrange 関数 $L\left(u_{i}, p, \theta, w_{i}, q, \xi, \Lambda\right)$ は次のようになる.

$$
\begin{aligned}
L= & w_{\theta} \cdot \frac{\int_{t_{1}}^{t_{2}} E_{\Omega_{D}}(\theta) d t}{\left[\int_{t_{1}}^{t_{2}} E_{\Omega_{D}}(\theta) d t\right]_{i n i}}+w_{u} \cdot \frac{\int_{t_{1}}^{t_{2}} E_{\Omega}(u) d t}{\left[\int_{t_{1}}^{t_{2}} E_{\Omega}(u) d t\right]_{i n i}} \\
& -\int_{0}^{T}\left\{t^{V}\left(u_{, t}, w\right)+a^{V}(u, w)+b^{V}(u, u, w)+c(w, p)-l(w)\right\} d t-\int_{0}^{T}\{c(u, q)\} d t \\
& -\int_{0}^{T}\left\{t^{H}\left(\theta_{, t}, \xi\right)+a^{H}(\theta, \xi)+b^{H}(u, \theta, \xi)+f_{q}^{H}(\xi)+\Lambda\left(\int_{\Omega} d x-M\right)\right.
\end{aligned}
$$

形状勾配密度関数 $G$ は次の様に導出できる. 


$$
\begin{aligned}
G= & \int_{0}^{T}\left\{-\frac{1}{\operatorname{Re}} w_{i, j} u_{i, j}-\frac{\partial \theta}{\partial t} \xi-\frac{1}{\operatorname{RePr}} \xi_{, i} \theta_{, i}+w_{u} \cdot \frac{1}{\left[\int_{t_{1}}^{t_{2}} E_{\Omega}(u) d t\right]_{i n i}} \cdot 2 \frac{1}{\operatorname{Re}} \varepsilon(u) \varepsilon(u)-\nabla_{n}(\xi \hat{q})-(\xi \hat{q}) \kappa\right. \\
& \left.-\nabla_{n}(\hat{h} \xi \theta)-(\hat{h} \xi \theta) \kappa+\nabla_{n}\left(\hat{h} \xi \hat{\theta}_{f}\right)+\left(\hat{h} \xi \hat{\theta}_{f}\right) \kappa\right\} d t+\Lambda
\end{aligned}
$$

また，この多目的問題に対する随伴方程式は，次の様に導出できる.

$$
\begin{aligned}
& \int_{0}^{T}\left\{t^{V}\left(u_{, t}^{\prime}, w\right)+a^{V}\left(u^{\prime}, w\right)+b^{V}\left(u^{\prime}, u, w\right)+b^{V}\left(u, u^{\prime}, w\right)+c\left(u^{\prime}, q\right)+b^{H}\left(u^{\prime}, \theta, \xi\right)+c\left(w, p^{\prime}\right)\right\} d t=w_{u} \cdot \frac{\int_{t_{1}}^{t_{2}} E_{\Omega}\left(u^{\prime}\right) d t}{\left[\int_{t_{1}}^{t_{2}} E_{\Omega}(u) d t\right]_{i n i}} \\
& \int_{0}^{T}\left\{t^{H}\left(\theta_{, t}^{\prime}, \xi\right)+a^{H}\left(\theta^{\prime}, \xi\right)+b^{H}\left(u, \theta^{\prime}, \xi\right)+f_{h}^{H}\left(\theta^{\prime}, \xi\right)\right\} d t=w_{\theta} \cdot \frac{\int_{t_{1}}^{t_{2}} E_{\Omega_{D}}\left(\theta^{\prime}\right) d t}{\left[\int_{t_{1}}^{t_{2}} E_{\Omega_{D}}(\theta) d t\right]_{i n i}}
\end{aligned}
$$

このようにして得られた随伴方程式から随伴変数を計算して, 形状勾配関数が評価できれば, 力法を適用するこ とが可能となる。

\section{5. 解 法}

\section{1 力法}

力法は領域変動量を意味する速度場 $\vec{V}$ を次の支配方程式に基づいて解く方法として提案されている (畔上, 1994).

$$
a^{E}(V, y)=-<G n, y>, \quad \forall y \in D
$$

ただし， $a^{E}(V, y)$ は $H^{1}(\Omega)$ において定義された線形弾性体のひずみエネルギーを与える双一次形式で, 変位分布 ベクトル関数 $u_{i}, v_{i}$ に対して次式で定義され (Azegami et al., 1997), その意味で, 力法は $H^{1}$ 勾配法とも呼ばれる (畔上, 2014).

$$
a^{E}(u, v)=\int_{\Omega} A_{i j k l} u_{k, l} v_{i, j} d x
$$

$A_{i j k l}$ は正定值性を有する剛性テンソルである. 式 (46) は, 速度場 $\vec{V}$ が負の形状勾配関数 $-G n_{i}$ を外力として作用 させたときの変位場として解析されることを示している. 力法に基づく領域変動は, 形状勾配関数を疑似弾性問 題の外力として作用させたときの変位場として求められる。 なお, 本解析は熱対流場解析であり, 簡単のために, 剛性テンソル $A_{i j k l}$ は次式で与えることにする.

$$
A_{i j k l}=\delta_{i k} \delta_{j l}
$$

\section{2 解析手順}

提案した形状決定解析は，次のステップを繰り返すことによって解析できる.

Step 1. 初期形状を与える.

Step 2. 状態方程式 (27), (28) に基づいて, 時間 $t=0$ から $t=T$ の方向へ, 流速分布 $u_{i}(\vec{x}, t)$, 圧力分布 $p(\vec{x}, t)$, 温度分布 $\theta(\vec{x}, t)$ を解析する。

Step 3. 目的汎関数が停留したと判断されれば解析を終了する.

Step 4. 得られた流速分布 $u_{i}(\vec{x}, t)$, 温度分布 $\theta(\vec{x}, t)$ を用いて, 随伴方程式 (29),(30), あるいは (44)(45) に基づい て, 時間 $t=T$ から $t=0$ の方向へ, 随伴流速分布 $w_{i}(\vec{x}, t)$, 随伴圧力分布 $q(\vec{x}, t)$, 随伴温度分布 $\xi(\vec{x}, t)$ を解析 する.

Step 5. これらの結果を用いて, 式 (33) あるいは式 (43) から形状勾配密度関数 $G$ を計算する. 


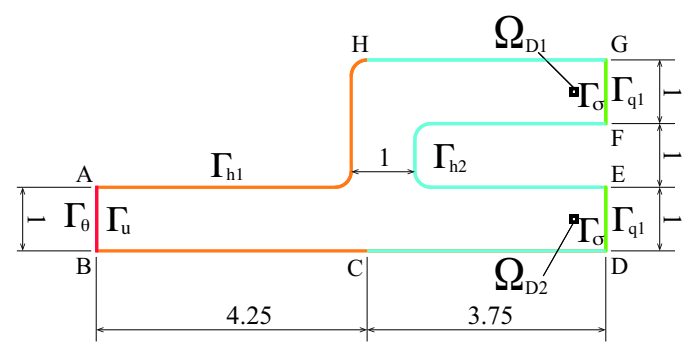

Fig. 2 Numerical model and boundary condition in branch channel problem

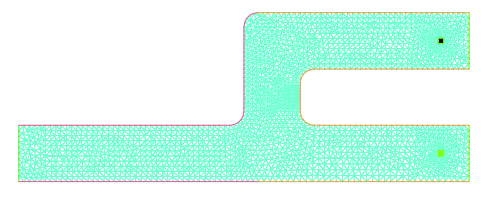

(a) Mesh

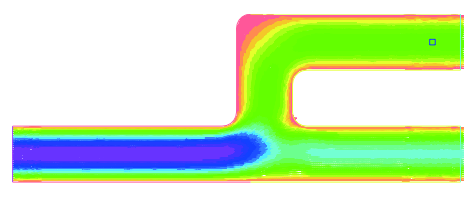

(b) Flow velocity

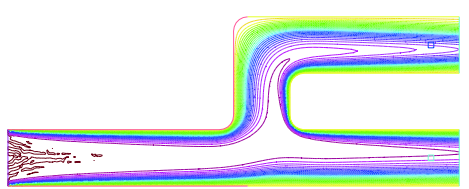

(c) Temperature

Fig. 3 Mesh, flow velocity and temperature distribution at final time $(\mathrm{t}=400)$ for initial shape in branch channel problem

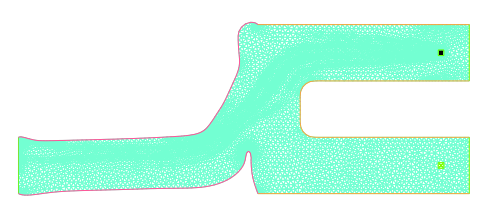

(a) Mesh

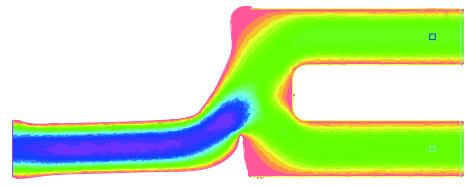

(b) Flow velocity

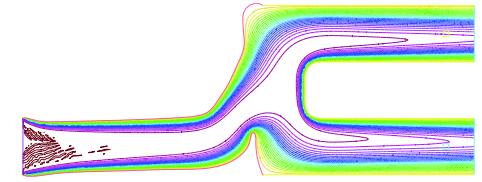

(c) Temperature

Fig. 4 Mesh, flow velocity and temperature distribution at final time $(\mathrm{t}=400)$ for identified shape in branch channel problem. In the identified shape, it is confirmed that the temperature distribution in sub-domain $\Omega_{D 1}$ agrees with that in sub-domain $\Omega_{D 2}$.

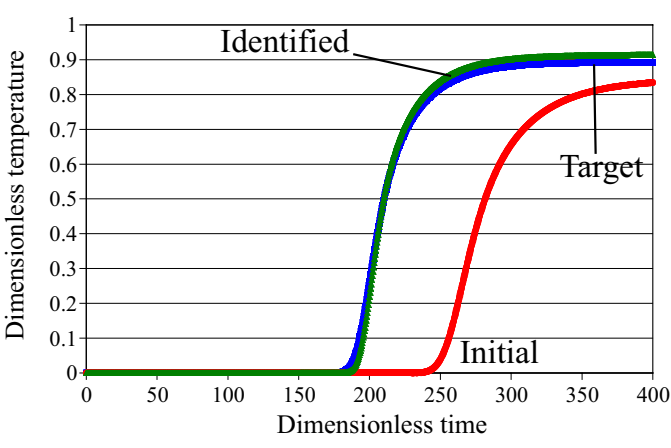

(a) Temperature history

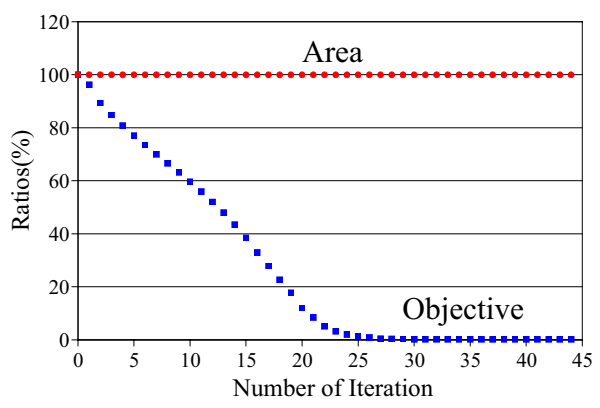

(b) Iterative history of objective functional

Fig. 5 Temperature history in sub-domain $\Omega_{D 1}$ and iterative history of objective functional in branch channel problem. The temperature history in sub-domain $\Omega_{D 1}$ agrees with the target temperature history in subdomain $\Omega_{D 2}$. The iterative history of objective functional approaches zero.

Step 6. 力法に基づいて式 (46) から速度場 $\vec{V}$ を計算して，形状を更新し，Step.2 に戻る.

\section{6. 解 析 例}

導出した形状勾配密度関数と力法を用いて解析した簡単な二次元問題の数值例を紹介する.

数值解析におけるプログラム開発は，Freefem++(Hecht, 2012),(大塚, 高石, 2014) に基づいて行った. Freefem++ における偏微分方程式の解法では，有限要素法の定式化で用いら机る弱形式の記述が，直接プログラミングの記 述として利用できるため，比較的容易に開発することが可能である。ささらに，Freefem++には，流秃解析における 
物質微分項の計算に対して, 特性曲線法有限要素近似に基づいて解析を行う関数 convect が実装されているため, 汎用プログラミング言語に比較してょり一層開発が容易である.

\section{1 温度分布履歴規定問題（分岐管）}

分岐管の解析モデルとして，図 2 のようなモデルを設定した。高温の熱流体が左側の基本境界 $\Gamma_{u}$ の $\mathrm{AB}$ より流 入し, 右側の二つの自然境界 $\Gamma_{\sigma}$ の $\mathrm{DE}, \mathrm{FG}$ から流出する。 二つの出口部における温度分布履歴均一化を目指し, 部分領域 $\Omega_{D 2}$ での温度分布履歴を目標值に設定して, 形状修正によって $\Omega_{D 1}$ の温度分布履歴が $\Omega_{D 2}$ の温度分布履 歴に一致するような形状を同定することを解析の目的とした。

流水場の境界条件は境界 $\mathrm{AB}$ で流入し，境界 $\mathrm{DE}, \mathrm{FG}$ は自然境界で表面力 $\hat{\sigma}_{i}=0$ で流出するとした。境界 $\mathrm{BC}$, $\mathrm{CD}, \mathrm{EF}, \mathrm{GH}, \mathrm{HA}$ は壁境界として $u_{i}=0$ とした. 温度場の境界条件は, 境界 $\mathrm{AB}$ を温度既知境界 $\Gamma_{\theta}$ として $\theta=1$ とした。 そして, 境界 $\mathrm{DE}, \mathrm{FG}$ は熱流束境界 $\Gamma_{q}$ として $q=0$ を設定し, 境界 $\mathrm{BC}, \mathrm{HA}$ は熱伝達境界 $\Gamma_{h 1}$ とし, 境界 $\mathrm{CD}, \mathrm{EF}, \mathrm{GH}$ は熱伝達境界 $\Gamma_{h 2}$ とし，いずれも熱伝達率 $h=1$, 外気温度 $\theta_{f}=0$ とした.レイノルズ数 $R e=100$, プラントル数 $P r=100$ として解析を行った.

初期条件は, 領域全体において $u_{i n i}=0, \theta_{i n i}=0$ とした。 内部発熱は無いものとして, 圧力 $p$ は平均值が 0 とな るよう一意に定めた。時間積分は, $t_{1}=0$ から $t_{2}=T=400$ を時間刻み $\Delta t=0.4$ で行った.

設計境界 $\Gamma_{\text {design }}$ は入り口付近の熱伝達境界 $\Gamma_{h 1}$ である壁境界 BC, HA とし, 出口付近の形状を変えることなく 出口温度を均一化することを目的とした。また，その他の境界は形状更新において完全に拘束し，形状更新にお いて領域の大きさを一定にする制約条件を設定した。なお，形状勾配密度関数の式 (33)における熱伝達境界に関 する項については無視して評価した.

流孔場解析（流速分布 $\vec{u}$ と圧力分布 $p$ ), 温度場解析（温度分布 $\theta$ ）, 随伴流孔場解析（随伴流速分布 $\vec{w}$ と随伴圧 力分布 $q$ ), 随伴温度場解析 (随伴温度分布 $\xi$ ) および形状更新解析（速度場 $\vec{V}$ ) の解析には, 全て FreeFem++(Hecht, 2012),(大塚, 高石, 2014) を利用して有限要素解析を行った。解析精度を保つために, 形状更新においては FreeFem++ 上の関数 adaptmesh を用いて再メッシュを行った. adptmesh は, 有限要素解析によって得られた状態変数の解の 精度を維持するためにアダプティブメッシュを生成する関数である. 本解析例では，力法による形状更新後にお いて, 生成メッシュ辺長さの上限值を初期メッシュ辺長さの最大值の $1 / 2$ 倍に設定し, 精度維持のために節点数が 増えるようなアダプティブメッシュを施した。なお，実際の形状更新において，形状更新とともに部分領域 $\Omega_{D 2}$ の温度履歴も変更されるため, その形状更新に基づく $\Omega_{D 2}$ の目標温度履歴の変化に追従して, $\Omega_{D 1} と \Omega_{D 2}$ の温度 分布履歴が同一になるように形状を決定する問題として解析した， $\Omega_{D 1}$ と $\Omega_{D 2}$ では，それぞれ有限要素で4 要素 分の領域で部分領域を定義した。

なお， $k$ 回目の形状修正における目的汎関数の值を $J^{[k]}$ とし，この值が次の停留判定条件を満たしたときに収束 したと判断し，この解析では， $\varepsilon=1 \times 10^{-3}$ とした。

$$
\frac{\left|J^{[k-1]}-J^{[k]}\right|}{J^{[k]}}<\varepsilon
$$

図 3 に初期形状における有限要素分割図，および最終時刻 $(t=T=400)$ での流速分布及び，温度分布を示す．図 4 に得られた同定形状における有限要素分割図, および最終時刻 $(t=T=400)$ での流速分布及び, 温度分布を示す. 図 5 (a) に温度規定領域 $\Omega_{D 1}$ 中央における初期形状での温度履歴, 目標温度履歴, 得られた同定形状での温度履歴 を示し, 図 5 (b) に形状更新の繰り返しに対する目的汎関数の収束履歴を示す. 図 3 と図 4 を比較をすると, 同定 された形状では, 出口温度が均一化されるように管路が等長化されるように分岐部が移動しており，目的に対し て妥当な形状更新を実現している. 実際に, 図 5(a) から, 同定形状の温度履歴が目標温度履歴に一致しているこ とが確認できる. また, 図 5(b) の結果から, 領域の大きさ一定の制約条件を満たしながら, 目的汎関数の值がゼ ロに収束していることが確認できる. なお, 目的汎関数の減少の様子が途中で変化するのは目標温度履歴が形状 更新毎に更新されているためである. 


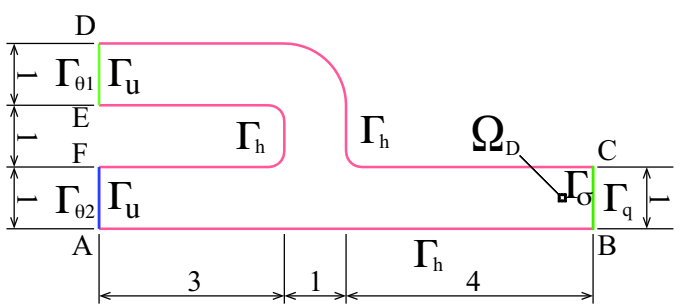

(a) Numerical model and boundary condition

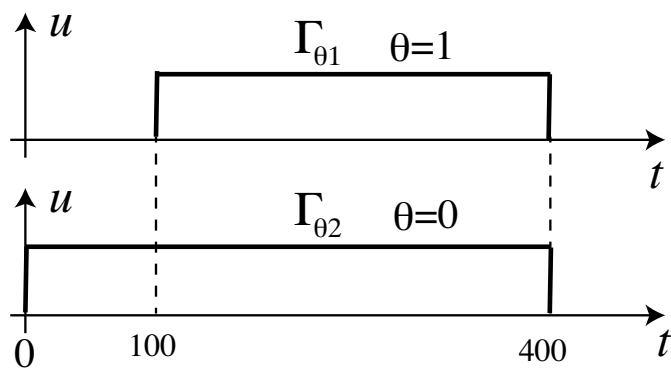

(b) Flow velocity on $\Gamma_{\theta 1}$ and $\Gamma_{\theta 2}$

Fig. 6 Numerical model and boundary condition in junction channel problem

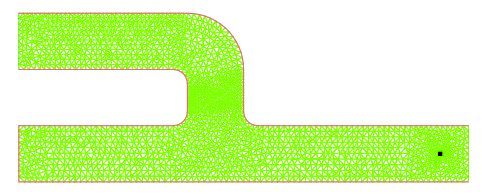

(a) Mesh

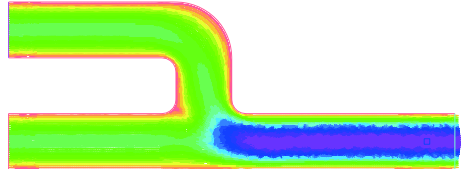

(b) Flow velocity

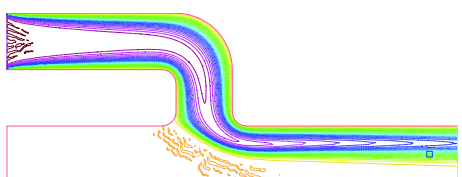

(c) Temperature

Fig. 7 Mesh, flow velocity and temperature distribution at final time $(\mathrm{t}=400)$ for initial shape in junction channel problem

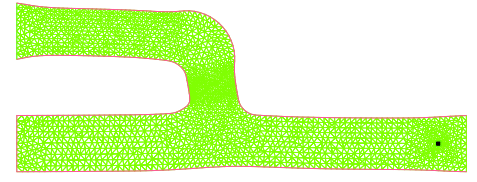

(a) Mesh

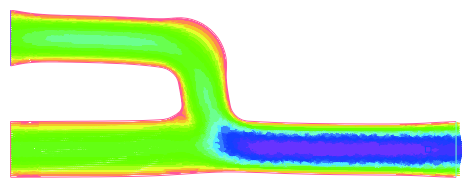

(b) Flow velocity

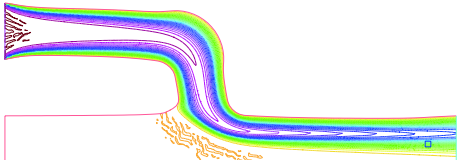

(c) Temperature

Fig. 8 Mesh, flow velocity and temperature distribution at final time $(\mathrm{t}=400)$ for identified shape in junction channel problem

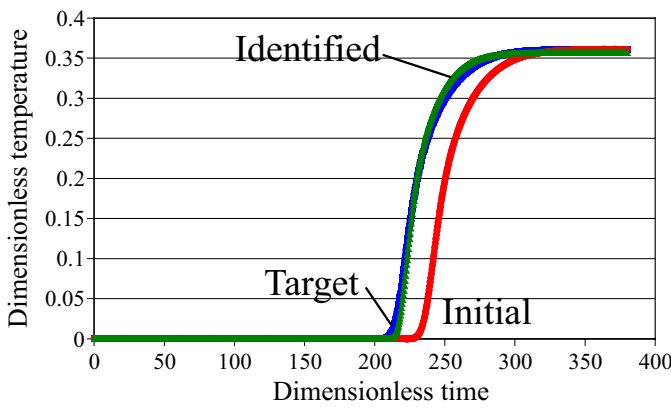

(a) Temperature history

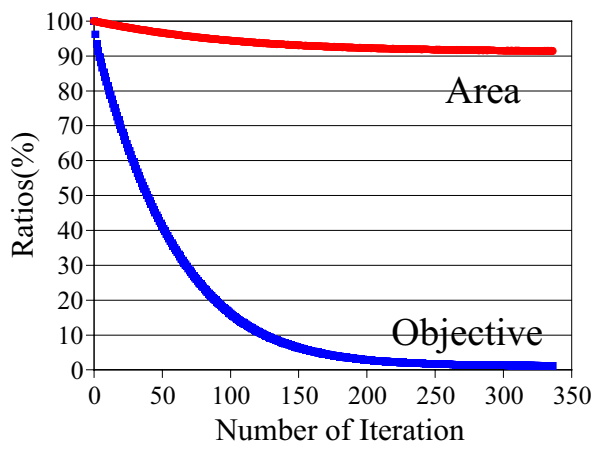

(b) Iterative history of objective functional

Fig. 9 Temperature history in sub-domain $\Omega_{D}$ and iterative history of objective functional in junction channel problem. The temperature history for the identified shape agrees with that for the target in sub-domain $\Omega_{D}$. The iterative history of objective functional approaches zero.

\section{2 温度分布履歴規定問題（合流管）}

次の温度分布履歴規定問題として，図 6 の合流管の解析モデルを設定した。

流れ場の境界条件は境界 $\mathrm{DE}, \mathrm{AF}$ で流入し，境界 $\mathrm{BC}$ は自然境界で表面力 $\hat{\sigma}_{i}=0$ で流出するとした。 $\mathrm{AB}, \mathrm{CD}$, $\mathrm{EF}$ は壁境界として $u_{i}=0$ とした. 温度場の境界条件は, 境界 $\mathrm{DE}$ を高温の温度既知境界 $\Gamma_{\theta 1}$, 境界 $\mathrm{AF}$ を低温の温 度既知境界 $\Gamma_{\theta 2}$ とし，それぞれの温度を $\theta=1, \theta=0$ とした。この解析例では，図 6(b) に示すように， $\theta=0$ の 低温熱流体が基本境界 $\Gamma_{\theta 2}$ から時刻 0 より流入し続け，時刻が 100 になった時に $\theta=1$ の高温熱流体が基本境界 $\Gamma_{\theta 1}$ からも流入が始まるとする。 また, $\mathrm{BC}$ は断熱境界 $\Gamma_{q}$ として $q=0$ を設定し, $\mathrm{AB}, \mathrm{CD}, \mathrm{EF}$ は熱伝達境界 $\Gamma_{h}$ 


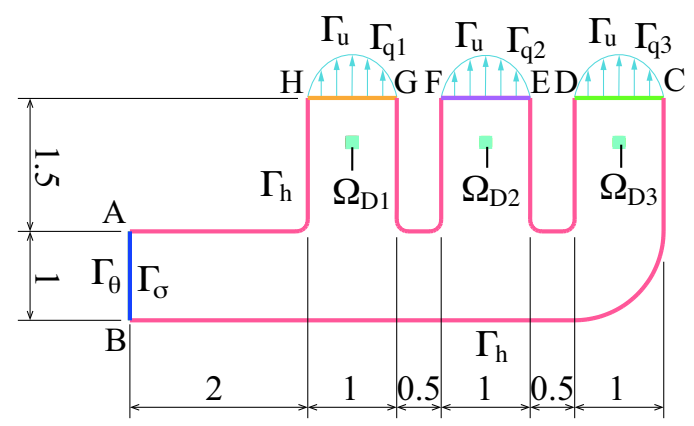

Fig. 10 Numerical model and boundary condition

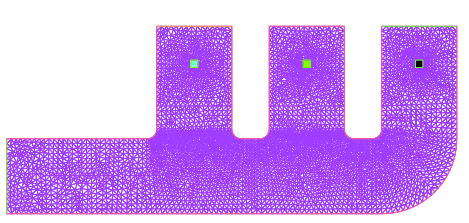

(a) Mesh

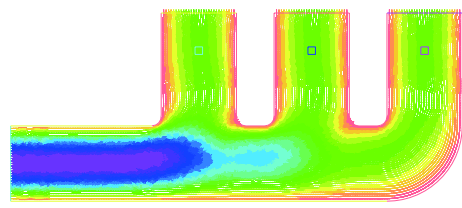

(b) Flow velocity

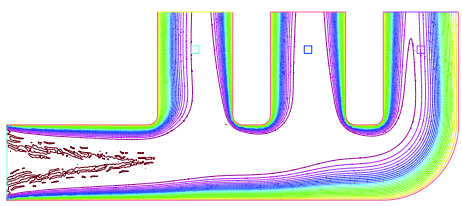

(c) Temperature

Fig. 11 Mesh, flow velocity and temperature distribution at final time $(\mathrm{t}=300)$ for initial shape

\section{とし, 熱伝達率 $h=1$, 外気温度 $\theta_{f}=0$ とした。}

本解析では, 温度規定領域 $\Omega_{D}$ において, 定常状態での温度分布は初期形状の場合と同様な温度分布を維持し, その温度分布履歴を 20 無次元化時間分だけ早めた履歴を目標值として，それを満足する形状を同定することを目 的とした。このような問題設定は，定常問題における解法では不可能であり，今回の非定常問題の解法によって実 現可能となっている.

レイノルズ数 $R e=100$, プラントル数 $P r=50$ として解析を行った。初期条件は, 領域全体において $u_{i n i}=0$, $\theta_{i n i}=0$ とした. 内部発熱は無いものとして, 圧力 $p$ は平均值が 0 となるよう一意に定めた. 時間積分は, $t_{1}=0$ から $t_{2}=T=400$ を時間刻み $\Delta t=0.4$ で行った.

設計境界 $\Gamma_{\text {design }}$ は熱伝達境界 $\Gamma_{h}$ である壁境界とし，その他の境界は形状更新において完全に拘束した．また，形 状更新の際には，面積一定の制約は考慮せず，形状勾配密度関数の式 (33) における熱伝達境界に関する項について は無視して評価した。前述の解析と同様に, 流れ場解析, 温度場解析および形状更新の解析には, 全て FreeFem++ を利用して有限要素解析を行った。この解析では，式(49)の停留判定条件は $\varepsilon=2 \times 10^{-3}$ とした.

図 7 に初期形状における有限要素分割図, および最終時刻 $(t=T=400)$ での流速分布及び, 温度分布を示す. 図 8 に得られた同定形状における有限要素分割図, および最終時刻 $(t=T=400)$ での流速分布及び, 温度分布を示す. 図 9(a) に温度規定領域 $\Omega_{D}$ 中央における初期形状での温度履歴，目標温度履歴，得られた同定形状での温度履歴 を示し, 図 9(b) に形状更新の繰り返しに対する目的汎関数の収束履歴を示す. 図 9(a)の結果から, 得られた同定形 状では温度規定領域 $\Omega_{D}$ における温度分布履歴が初期形状に比較して, 無次元化時間で 20 早めた結果となり, 目 標温度履歴に一致していることが確認できる. また, 図 9(b) の結果から, 目的汎関数の值がゼロに収束している ことが確認できる。

以上の結果から, 非定常強制熱対流場の部分領域において, 温度分布履歴を規定する形状決定問題の解法の妥 当性を確認することができた。

\section{$6 \cdot 3$ 温度分布履歴規定と散逸エネルギー最小化の多目的問題}

複数の規定領域で温度分布を規定する問題として, 図 10 のような形状を設定した。本解析では, 目標温度 $\theta_{D}$ に対して, 規定領域 $\Omega_{D 1}, \Omega_{D 2}, \Omega_{D 3}$ の温度分布履歴の平均值を与えて出口温度分布を均一化すること，および全 領域での散逸エネルギー最小化を試みた.

流れ場の境界条件は基本境界 $\Gamma_{u}$ の $\mathrm{HG}, \mathrm{FE}, \mathrm{DC}$ で流出し, 自然境界 $\Gamma_{\sigma}$ の $\mathrm{AB}$ で表面力 0 で流入するとした. 


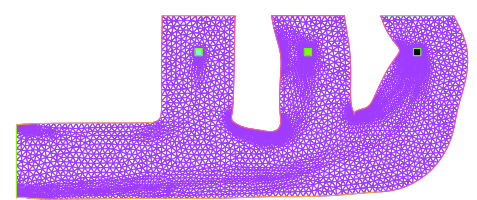

(a) Mesh

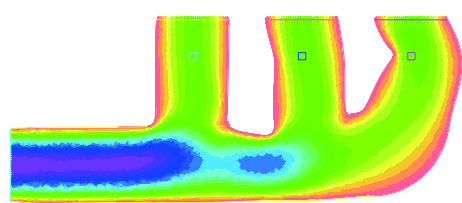

(b) Flow velocity

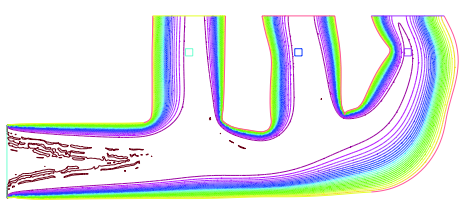

(c) Temperature

Fig. 12 Mesh, flow velocity and temperature distribution at final time $(\mathrm{t}=300)$ for identified shape, $\left(\right.$ Case A: $\left.w_{\theta}=1.0, w_{u}=0\right)$

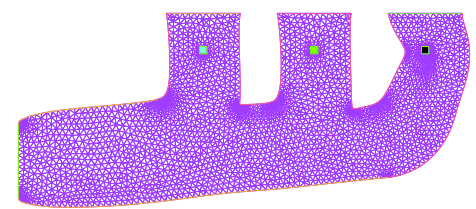

(a) Mesh

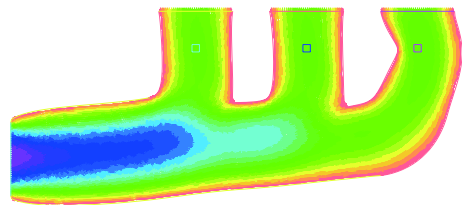

(b) Flow velocity

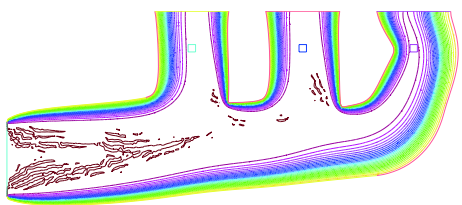

(c) Temperature

Fig. 13 Mesh, flow velocity and temperature distribution at final time $(t=300)$ for identified shape, (Case $B$ : $\left.w_{\theta}=0.5, w_{u}=0.5\right)$. Because the dissipation energy minimization is considered in Case $\mathrm{B}$, the identified shape that is smoother than Case $\mathrm{A}$ is obtained.

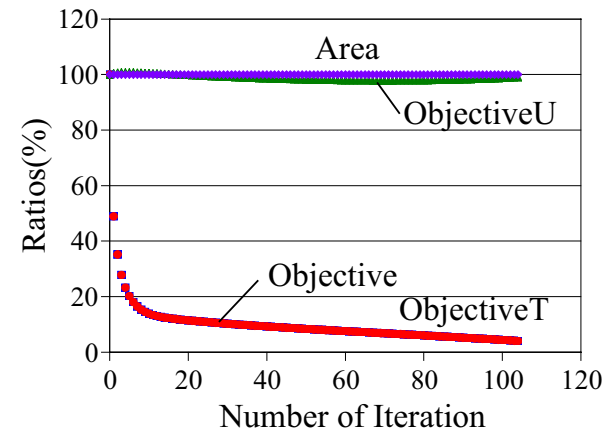

(a) Case A: $w_{\theta}=1.0, w_{u}=0$

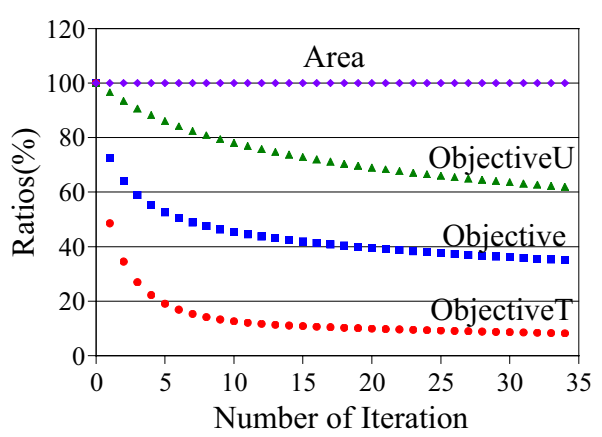

(b) Case B: $w_{\theta}=0.5, w_{u}=0.5$

Fig. 14 Iterative history of objective functional. The iterative history of objective functional approaches zero in Case A. The iterative history of objective functional decreases and converges to the minimum in Case B.

境界 $\mathrm{BC}, \mathrm{DE}, \mathrm{FG}, \mathrm{HA}$ は壁境界として $u_{i}=0$ とした. また, 温度場の境界条件は, $\mathrm{AB}$ を温度既知境界 $\Gamma_{\theta}$ として $\theta=1$ とした。 そして境界 $\mathrm{HG}, \mathrm{FE}, \mathrm{DC}$ はそれぞれ断熱境界 $\Gamma_{q 1}, \Gamma_{q 2}, \Gamma_{q 3}$ として $q=0$ を設定し, 境界 $\mathrm{BC}, \mathrm{DE}$, FG, HA は熱伝達境界 $\Gamma_{h}$ として熱伝達率 $h=1$, 外気温度 $\theta_{f}=0$ とした. 初期条件は, 領域全体において $u_{i n i}=0$, $\theta_{i n i}=0$ とした. 内部発熱は無いものとして, 圧力 $p$ は平均值が 0 となるよう一意に定めた。時間積分は, $t=0$ か ら $t=T=300$ を時間刻み $\Delta t=0.6$ で行った. プラントル数 $P r=100$, レイノルズ数 $R e=100$ として解析を行った. 設計境界 $\Gamma_{\text {design }}$ は熱伝達境界 $\Gamma_{h}$ である壁面とし，ほかの境界は形状更新の際には完全に拘束し， adaptivemeshの 機能を使用した。また，面積一定の制約を与えた。感度の式 (43) における熱伝達境界に関する項については無視 して感度を評価した。式 (49) の停留判定条件は $\varepsilon=2 \times 10^{-3}$ とした。なお，今回の解析では，時間区間 $[0, T]$ の 全体にわたって温度分布履歴規定を試みることが困難であったため, 温度分布履歴規定と散逸エネルギー最小化 の時間範囲を $t_{1}=200, t_{2}=300$ とし, Case $\mathrm{A}\left(w_{\theta}=1.0, w_{u}=0\right)$, Case B $\left(w_{\theta}=0.5, w_{u}=0.5\right)$ として解析した結果を紹介 する.

図 11 に初期形状における有限要素分割図，および最終時刻 $(t=T=300)$ での流速分布，温度分布を示す．図 12 および図 13 に, Case A $\left(w_{\theta}=1.0, w_{u}=0\right)$, Case B $\left(w_{\theta}=0.5, w_{u}=0.5\right)$ に対して得られた同定形状における有限要素分割 図, 最終時刻 $(t=T=300)$ での流速分布, 温度分布をぞれぞれ示す. Case B では, 散逸エネルギー最小化を考慮し ているため（エネルギー損失低滅のため），Case A に比較してやや滑らかな流路形状が得られている.

図 14 に, Case A, Case B における形状更新の繰り返しに対する目的汎関数の収束履歴を示す.Case A における 
総和目的汎関数 (Objective) は, 温度分布 2 乗誤差積分 (Objective T) と同一となり, 領域の大きさ一定の制約条件 を満たしながら, 総和目的汎関数はほぼゼロ近くになり収束していることが確認できる。なお，完全にゼロにな らない理由は, 今回の問題設定では規定領域 $\Omega_{D 1}, \Omega_{D 2}, \Omega_{D 3}$ の温度分布履歴の平均值を目標温度 $\theta_{D} に し て お り$, その設定にやや無理があったためであると考えられる。また, Case Bでは, 領域の大きさ一定の制約条件を満た しながら, 温度分布 2 乗誤差積分 (Objective T), 散逸エネルギー (Objective U), 総和目的汎関数 (Objective) の值が ともに滅少して収束していることが確認できる。

\section{7. ま と め}

本論文では，非定常強制熱対流場の部分領域において温度分布履歴を規定する問題，また温度分布履歴規定と 対流場における散逸エネルギー最小化の多目的問題の二つの形状決定問題を取り上げて, その数值解析法を提案 した。 二つの形状決定問題の定式化を行い，それぞれの問題に対する形状勾配密度関数を導出し，それらの形状 勾配関数に基づいて力法を適用した簡単な解析例から，提案した手法の妥当性を示した.

\section{文献}

Alexandersen, J., Aage, N., Andreasen, C. S. and Sigmund, O., Topology optimization for natural convection problems, International Journal for Numerical Methods in Fluids, Vol.76, No.10(2014), pp.699-721.

畔上秀幸, 領域最適化問題の一解法, 日本機械学会論文集 A 編, Vol. 60, No. 574 (1994), pp. 1479-1486.

畔上秀幸, 形状最適化問題の正則化解法, 日本応用数理学会論文誌, Vol. 24, No. 2 (2014), pp. 83-138.

Azegami, H., Kaizu, S., Shimoda, M. and Katamine, E., Irregularity of shape optimization problems and an improvement technique, Computer Aided Optimum Design of Structures V, OPTI 97, edited by Hernandez, S. and Brebbia, C.A. , Computational Mechanics Publications, Southampton (1997), pp.309-326.

Hecht, F., New development in FreeFem++, Journal of Numerical Mathematics, Vol.20, No. 3-4 (2012), pp.251-265. $65 \mathrm{Y} 15$.

片峯英次, 畔上秀幸, 粘性流れ場領域最適化問題の解法（力法によるアプローチ）, 日本機械学会論文集 B 編, Vol. 60, No. 579 (1994), pp. 3859-3866.

Katamine, E., Azegami, H., Tsubata, T. and Ito, S., Solution to shape optimization problems of viscous flow fields, International Journal of Computational Fluid Dynamics, Vol. 19, No.1 (2005), pp.45-51.

片峯英次, 河瀬賀行, 畔上秀幸, 強制熱対流場の形状最適化, 日本機械学会論文集 B 編, Vol. 73, No. 733 (2007), pp. 1884-1891.

片峯英次, 桐山恭幸, 畔上秀幸, 強制熱対流場における多目的形状最適化, 日本機械学会論文集 B 編, Vol. 79, No. 806 (2013), pp. 2239-2253.

久保田正人, 徳田茂史, 谷口真, 野口泰, Adjoint 法による熱および濃度目的 CFD 逆解析技術の開発と実機適用, 自動車技術会論文集, Vol. 48, No. 2 (2017), pp. 505-510.

桃瀬一成, 河野紘明, 河原源太, 熱対流場における形状感度解析と最適化アプローチ, 日本機械学会熱工学コンファ レンス 2009 講演論文集 (2009), pp. 177-178.

大塚厚二, 高石武史, 有限要素法で学ぶ現象と数理-FreeFem++数理思考プログラミング-, (2014), 共立出版.

Park, H. M. and Ku, J. H., Shape identification for natural convection problems, Communications in Numerical Methods in Engineering, Vol. 17 (2001), pp.871-880.

Park, H. M. and Shin, H. J., Shape identification for natural convection problems using the adjoint variable method, Journal of Computational Physics, Vol. 186 (2003), pp.198-221.

Yaji, K., Yamada, T., Kubo, S., Izui, K. and Nishiwaki, S., A topology optimization method for a coupled thermalfluid problem using level set boundary expressions, International Journal of Heat and Mass Transfer, Vol.81(2015), pp.878-888.

Yan, W. and Gao, Z., Shape optimization in the Navier-Stokes flow with thermal effects, Numerical Method for Partial Differential Equations, Vol. 30, No. 5(2013), pp.1700-1715. 
Yan, W., Wang, A. and Guan, G., A numerical method for shape optimal design in the Oseen flow with heat transfer, Journal of Applied Mathematics and Physics, Vol.3(2015), pp.1295-1307.

Yan, W., Su, J. and Jing, F., Shape reconstruction for unsteady advection-diffusion problem by domain derivative method, Abstract and Applied Analysis, Vol.2014 (2014), Article ID 673108, 7 pages.

Yan, W., Hou, J. and Gao, Z., Shape identification for convection-diffusion problem based on the continuous adjoint method, Applied Mathematics Letters, Vol.64 (2017), pp.74-80.

\section{References}

Alexandersen, J., Aage, N., Andreasen, C. S. and Sigmund O., Topology optimization for natural convection problems, International Journal for Numerical Methods in Fluids, Vol.76, No.10(2014), pp.699-721.

Azegami, H., Solution to domain optimization problems, Transactions of the Japan Society of Mechanical Engineers, Series A, Vol.60, No.574(1994), pp. 1479-1486(in Japanese).

Azegami, H., Regularized solution to domain optimization problems, Transactions of the Japan Society for Industrial and Applied Mathematics, Vol.24, No.2(2014), pp. 83-138(in Japanese).

Azegami, H., Kaizu, S., Shimoda, M. and Katamine, E., Irregularity of shape optimization problems and an improvement technique, Computer Aided Optimum Design of Structures V, OPTI 97, edited by Hernandez, S. and Brebbia, C.A. , Computational Mechanics Publications, Southampton (1997), pp.309-326.

Hecht, F., New development in FreeFem++, Journal of Numerical Mathematics, Vol.20, No. 3-4 (2012), pp.251-265. $65 \mathrm{Y} 15$.

Katamine, E. and Azegami, H., Solution to viscous flow field domain optimization problems (Approach by the Traction Method), Transactions of the Japan Society of Mechanical Engineers, Series B , Vol.60, No.579(1994),pp. 3859-3866 (in Japanese).

Katamine, E., Azegami, H., Tsubata, T. and Ito, S., Solution to shape optimization problems of viscous flow fields, International Journal of Computational Fluid Dynamics, Vol. 19, No.1 (2005), pp.45-51.

Katamine, E., Kawase, Y. and Azegami, H., Shape optimization of forced heat-convection fields, Transactions of the Japan Society of Mechanical Engineers, Series B , Vol.73, No.733(2007),pp. 1884-1891 (in Japanese).

Katamine, E., Kiriyama, Y. and Azegami, H., Multi objective shape optimization in forced heat-convection fields, Transactions of the Japan Society of Mechanical Engineers, Series B , Vol.79, No.806(2013),pp. 2239-2253 (in Japanese).

Kubota, M., Tokuda, S., Taniguchi, M. and Noguchi, Y., Development of CFD inverse analysis technology targeting heat or concentration performance by using the transient adjoint method and its application to the actual components, Transactions of Society of Automotive Engineers of Japan, Vol. 48, No. 2 (2017), pp. 505-510 (in Japanese).

Momose, K., Kawano, H. and Kawahara, G., An approach for shape optimization with sensitivity analysis in heat convection fields, Proceedings of the Thermal Engineering Conference 2009 (2009), pp.177-178((in Japanese).

Ootsuka, K. and Takaishi ,T., Finite element analysis using mathematical programming language FreeFem++(2014), Kyoritsu (in Japanese).

Park, H. M. and Ku, J. H., Shape identification for natural convection problems, Communications in Numerical Methods in Engineering, Vol. 17 (2001), pp.871-880.

Park, H. M. and Shin, H. J., Shape identification for natural convection problems using the adjoint variable method, Journal of Computational Physics, Vol. 186 (2003), pp.198-221.

Yaji, K., Yamada, T., Kubo, S., Izui, K. and Nishiwaki, S., A topology optimization method for a coupled thermalfluid problem using level set boundary expressions, International Journal of Heat and Mass Transfer, Vol.81(2015), pp.878-888.

Yan, W. and Gao, Z., Shape optimization in the Navier-Stokes flow with thermal effects, Numerical Method for Partial Differential Equations, Vol. 30, No. 5(2013), pp.1700-1715.

Yan, W., Wang, A. and Guan, G., A numerical method for shape optimal design in the Oseen flow with heat transfer, Journal of Applied Mathematics and Physics, Vol.3(2015), pp.1295-1307. 
Yan, W., Su, J. and Jing, F., Shape reconstruction for unsteady advection-diffusion problem by domain derivative method, Abstract and Applied Analysis, Vol.2014 (2014), Article ID 673108, 7 pages.

Yan, W., Hou, J. and Gao, Z., Shape identification for convection-diffusion problem based on the continuous adjoint method, Applied Mathematics Letters, Vol.64 (2017), pp.74-80. 